Plastic and Reconstructive Surgery

Issue: Volume 111(4), 1 April 2003, pp 1567-1568

Copyright: @2003American Society of Plastic Surgeons

ISSN: 0032-1052

Accession: 00006534-200304010-00043

\title{
CLEAR VISUALIZATION OF CAPSULAR CALCIFICATIONS AROUND BREAST IMPLANTS
}

Valdatta, Luigi M.D.; Tuinder, Stefania M.D.; Thione, Alessandro M.D.; Buoro, Mara M.D.; Mortarino, Christian M.D.;

Fidanza, Carlo M.D.; Protasoni, Marina M.D.; Reguzzoni, Marcella B.Sc.

Author Information

Laboratory of Human Morphology; Faculty of Medicine; University of Insubria; Varese, Italy

Ospedale di Circolo-Fondazione Macchi; Varese, Italy

Correspondence to Dr. Valdatta

Ospedale di Circolo-Chirurgia Plastica

Viale Borri 57

21100 Varese, Italy

chirplas@libero.it

We would like to show how calcium phosphate deposits can be easily visualized in overlapping images obtained using a scanning electron microscope and images obtained by energy-dispersive x-ray analysis. We analyzed the capsula of a secondgeneration, 1 gel-filled breast implant inserted into the subcutaneous plane 31 years earlier; the patient requested explantation of the implant because of the occurrence of Baker IV capsular contracture. $\underline{2}$

Optic microscope: The tissue specimens were fixed in formalin, dehydrated in ascending grades of alcohol, and embedded in paraffin. The sections obtained by using the Leica microtome (Leica Microsystems, Wetzlar, Germany) were collected on slides, stained with hematoxylin and eosin, observed under a Nikon Eclipse E600 microscope (Nikon, Tokyo, Japan), and photographed with a Polaroid DMC digital camera (Polaroid, Waltham, Mass.). Observation of the capsula under the optic microscope revealed the presence of collagenous fibrous tissue. The collagen fibers were irregularly disposed. Very few fibroblasts were present in this tissue, which had dystrophic, calcificated areas. 
Electron microscope: The samples were fixed in $2.5 \%$ glutaraldehyde and $2 \%$ paraformaldehyde in $\mathrm{pH} 7.4$ cacodylate buffer, postfixed in $1 \%$ osmic acid in $1 \mathrm{M}$ cacodylate buffer, dehydrated in ascending grades of ethanol and propylenoxide, and embedded in Epon 812. They were then cut with an RMC Ultramicrotome (RMC Products, Boeckeler Instruments, Inc., Tucson, Ariz.) into sections that were $80 \mathrm{~nm}$ and $400 \mathrm{~nm}$ thick. The ultrathin sections were collected on copper grids, overstained with uranyl citrate and lead acetate, and observed with a JEOL 1010 transmission electron microscope (JEOL USA Inc., Peabody, Mass.).

Semithin sections were collected on a carbon stub, sputtered with graphite, and observed with a Philips XL30 scanning electron microscope (FEI Company, Hillsboro, Ore.) using the backscatter electron method and energy-dispersive $x$-ray analysis. The pictures obtained from the scanning electron microscope were digitally acquired at a different magnification, and the acquisition range was between $5 \mathrm{kV}$ and $20 \mathrm{kV}$. The spectra were obtained with a uniform acquisition time, at $20 \mathrm{kV}$, with a punctiform analysis.

The maps were obtained on the same region as the acquired images and microanalysis, digitally collected at $20 \mathrm{kV}$, elaborated using the $\mathrm{N} \times \mathrm{N}$ filter of an image analysis program (Analysis), and successively superimposed on the respective pictures using an image elaboration program (Photoshop 5.0; Adobe Systems Inc., San Jose, Calif.).

Observation of the specimens under a scanning electron microscope and a transmission electron microscope revealed the presence of aggregates of needleshaped crystals; they were $600 \mathrm{~nm}$ in length and they constituted agglomerates of 1 to $1.5 \mu \mathrm{m}$ in diameter (Fig. 1, above, left).

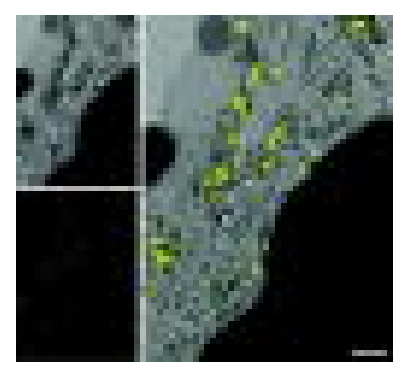

Fig. 1

Energy-dispersive $\mathrm{x}$-ray analysis of the crystals revealed the presence of calcium and phosphorus, but neither silicium nor titanium was found (Fig. 1, below, left).

Needle-shaped, electron-opaque crystals present in the backscatter electron images (Fig. 1, above, left) were calcium phosphate deposits; this assertion can be visually demonstrated by the perfect overlapping of the two maps (Fig. 1, right). This map (Fig. 1, right) could be particularly useful to visually distinguish 
calcium phosphate deposits from any other kind of electron-opaque deposit (if present) in the context of the capsula itself.

Luigi Valdatta, M.D.

Stefania Tuinder, M.D.

Alessandro Thione, M.D.

Mara Buoro, M.D.

Christian Mortarino, M.D.

Carlo Fidanza, M.D.

Marina Protasoni, M.D.

Marcella Reguzzoni, B.Sc.

\section{Back to Top}

\section{References}

1. Peters, W., Kenneth, P., and Dennis, S. Calcification associated with silicone breast implants: Incidence, determinants, and characterization. Ann. Plast. Surg. 41: 348, 1998. Buy Now [Context Link]

2. Spear, S. L., and Baker, J. L., Jr. Classification of capsular contracture after prosthetic breast reconstruction. Plast. Reconstr. Surg. 96: 1119, 1995. Buy Now 
[Context Link] 